\section{Cave: temporäre Hennatätowierungen!}

\author{
Hennatätowierungen gehören in der arabischen Welt und Teilen \\ Asiens zur gängigen Dekoration der Haut. Die Farbe wird dabei in \\ girlandenförmigen Mustern aufgebracht, um nach etwa 2 Wochen \\ wieder zu verblassen. Auch wenn Henna als wenig allergisierend \\ gilt, ist doch eine differenzierte Betrachtung angebracht.
}

\begin{abstract}
- ine Touristin hatte sich in Dubai mit Henna tätowieren lassen und dies problemlos toleriert. Etwa $1 \mathrm{Jahr}$ später ließ sie erneut eine Hennatätowierung durchführen. 10 Tage danach entwickelten sich entlang der Applikationsstellen ekzematöse Veränderungen. Unter einer systemischen und lokalen Glukokortikoidtherapie kam es zu einer schnellen Besserung.

1 Woche später entwickelte sich nach Tragen eines schwarzen Kleidungsstücks ein diesmal generalisiertes Ekzem. Bei der nachfolgenden Epikutantestung fand sich eine stark positive Reaktion auf para-Phenylendiamin, weniger ausgeprägt auf Dispersionsorange 3, Bismarck Brown R sowie para-Aminoazobenzol. Es war also davon auszugehen, dass über die Hennatätowierung eine Kontaktsensibilisierung erfolgt war, wobei aber nicht
\end{abstract}

Henna als solches, sondern die beigemischten Farbstoffe die ekzemauslösenden Kontaktallergene waren.

Dieser Fallbericht bestätigt damit frühere Mitteilungen über den Erwerb von Kontaktsensibilisierungen gegen Textilfarbstoffe, welche Henna bei Hauttätowierungen beigemischt werden können. Auf die Möglichkeit von Kreuzreaktionen mit anderen Paragruppensubstanzen wird hingewiesen. Die Autoren verzichteten offensichtlich wegen der äußerst selten vorkommenden Kontaktallergie gegen das Henna selbst auf dessen Austestung. Nach Erfahrung des Referenten kann sich aber nach Anwendung von Henna als Haarfärbemittel eine Allergie vom Soforttyp entwickeln.

Fazit: Bei Verdacht auf Henna-Allergie nach Tätowierung sollte an Kontaktsensibilisierungen gegen Textilfarb-

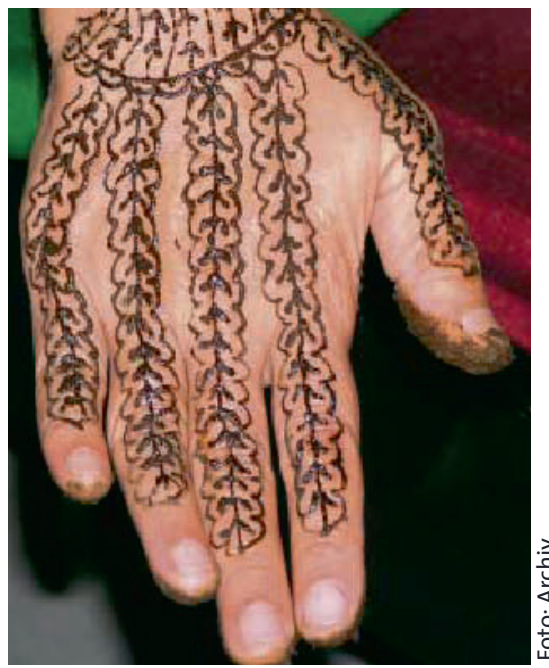

Temporäre Hennatätowierungen, sog. Temptoos oder auch Mendis, erfreuen sich zunehmender Beliebtheit.

stoffe gedacht werden. Aus Gründen der Prophylaxe sollte Urlaubern von temporären Hennatätowierungen abgeraten werden.

Dr. Dieter Bruchhausen, Wuppertal

\section{Literatur}

Boschnakow A. Temporäre Tätowierung mit Henna induziert Kontaktallergie auf Textilfarbstoffe. JDDG 2003; 1: 962-4

\title{
Autoallergene im Allergikerschweiß
}

\section{Der öfter zu beobachtende therapeutische Effekt von Bädern und Duschen bei Neurodermitis deutet auf einen das Ekzem verstärken- den Faktor auf der Hautoberfläche hin. Da liegt es nahe, humanen Schweiß genauer auf seine Autoallergenität hin zu untersuchen.}

\footnotetext{
E ine japanische Arbeitsgruppe sam- melte Schweiß von Patienten mit Neurodermitis, von Patienten mit allergischer Rhinitis ohne begleitende Neurodermitis sowie von Gesunden. Im intradermalen Test mit Schweiß, gleich ob dieser von Atopikern oder Gesunden stammte, reagierten $84,8 \%$ der Neurodermitiker, hingegen nur $11 \%$ der Gesunden positiv. In gleicher Weise positiv reagierten $71 \%$ der Patienten mit allergischer Rhinitis.

Parallel zu diesen Befunden setzten Basophile von Neurodermitikern nach
}

Schweißinkubation Histamin frei, nicht aber die von Gesunden. Diese Histaminliberierung erwies sich als IgE-abhängig. Entfernte man nämlich $\mathrm{IgE}$ von der Oberfläche der Basophilen, so blieb die Histaminfreisetzung aus. Gleicherweise inaktiv verhielten sich IgE-befreite Basophile, wenn sie zunächst mit einem unspezifischen Myelom-IgE beschichtet und danach mit Schweiß inkubiert wurden. Wurden dagegen die Basophilen gesunder Probanden mit Serum von Neurodermitikern sensibilisiert, liberierten sie nach Schweißinku- bation ebenfalls Histamin. Das Ausmaß der durch Schweiß auslösbaren Hautreaktion sowie auch die Histaminausschüttung der Basophilen waren unabhängig von Schwere und Art der allergischen Erkrankung.

Offensichtlich enthält Allergikerschweiß generell Allergene, die bei Erkrankten Histamin freisetzen können. Es handelt sich also um Autoallergene, die nur mit auf Mastzellen oder Basophilen fixierten IgE-Antikörpern (IgEAutoantikörper) reagieren. Die Autoren nehmen an, daß die Schweißallergene aus den Schweißdrüsen stammen.

Dr. Dieter Bruchhausen, Wuppertal

\section{Literatur}

Hide $M$, Tanaka T, Yamamura Y, Koro 0 , Yamamoto S. IgE-mediated hypersensitivity against human sweat antigen in patients with atopic dermatitis. Acta Derm Venereol. 2002; 82: $335-40$ 